\title{
STUDY OF EFFECTIVENESS OF EDUCATIONAL COMMUNICATION IN THE PROCESS OF DISTANCE LEARNING OF AGRICULTURAL ENGINEERS
}

\author{
Stanislav Nikolaenko ${ }^{1}$, Maria Bondar ${ }^{1}$, Oksana Bulgakova ${ }^{1}$, Lyubov Shymko ${ }^{1}$, Ilmars Dukulis ${ }^{2}$ \\ ${ }^{1}$ National University of Life and Environmental Sciences of Ukraine, Ukraine; ${ }^{2}$ Latvia University of \\ Life Sciences and Technologies, Latvia \\ semjons@apollo.lv
}

\begin{abstract}
At the beginning of 2020, due to the rapid and global spread of the Covid-19 pandemic, educational institutions were forced to immediately switch to a purely distance learning form, which has had an ambiguous effect on all the structural elements of the education system. In addition to high-quality fundamental training and mastering the theoretical foundations of engineering calculations, it is no less important for engineering graduates to acquire sustainable skills and abilities to carry out practical activities - experimenting, researching, testing, modeling, etc. Most of the above-mentioned skills in the conditions of regular, full-time education were obtained in the form of scientific circles, laboratory works, practical classes, training and production practices, and the like. With the pandemic and total distance learning, against the background of established communication channels like systems: Moodle; Zoom; Google Classroom service; G Suite for Education, Office 365 Education, communication tools became popular: Skype; Google Meet; Webex Meet; Teams, messengers Viber, WhatsApp, Telegram, etc. That is, for distance learning, a wide range of communication channels are available. However, due to technical reasons, not all of them are equally effective. The purpose of this research: to study the effectiveness of educational communications in the conditions of distance learning at the Mechanical and Technological Faculties.
\end{abstract}

Keywords: higher education, engineering, pandemic, distance learning, communication.

\section{Introduction}

The rapid spread of COVID-19 has caused the global community, for the first time, to be faced with the urgent need to switch to distance learning. According to the UN “...by mid-April 2020, the pandemic has affected $94 \%$ of students, that is, 1.58 billion children and young people (from preschoolers to university students) in 200 countries" [1]. Wearing masks, social distancing, months of quarantine, and distance learning have become firmly embedded in the minds of people in the vast majority of the world. For higher professional education of agricultural universities in most countries the experience of distance learning was not new. Back in the early 2000 by the orders of the MES of Ukraine the legal framework based on the requirements of the National University of Life and Environmental Sciences of Ukraine a system of distance learning was built. The development of information technologies has created an opportunity to introduce an educational and informational portal, which is part of the information and educational environment of the National University of Life and Environmental Sciences of Ukraine [2] in the educational process. The resource is designed for distance and correspondence forms of education, as well as to support the full-time form of education. The work of learning and information portal is organized on the basis of the use of the distance learning platform "Modular Object Oriented Distance Learning Environment" (Moodle). With the help of this system the student can remotely, via the Internet, open an e-learning course, study the educational material, which can be presented in the form of different types of information resources (text, video, animation, presentation, electronic manuals), do the task and send it for review, take electronic tests. The teacher has the ability to independently create e-learning courses and conduct distance learning, send messages to students, distribute, collect and check tasks, keep electronic logs of grades and attendance, customize various course resources, etc. [3].

However, despite the accumulated experience, in certain aspects, the urgent transition to distance learning associated with quarantine restrictions has revealed problematic places in the system of engineering training. In particular, the basic and natural educational communication - " teacher $\leftrightarrow$ studen t" has moved to "on line". It is the effectiveness of mutual communication between a teacher and a student that has a decisive influence on a graduate's competence and is defined as the integration of knowledge, skills, and attitudes that allow him/her to perform a certain task in vaguely defined and unique environments [4]. Therefore, research on the effectiveness of educational communications in the process of distance learning for engineers in agricultural engineering, technical service and commodity agro-industrial production is an important scientific and practical task. Fernando Reimers, Andreas Schleicher, Jaime Saavedra, and Saku Tuominen published the first module of a series 
back in late March 2020 with the overall goal of promoting a rapid process of designing and implementing adaptive responses to emerging threats and challenges in education, as well as measures to protect educational opportunities for young people during and after a pandemic. In the second module [5], the first set of online educational resources to support continuity of teaching and learning during the COVID-19 pandemic is presented. The resources were compiled from the survey responses of the first module, and additional sources were included to improve the list, which aims to support the continuity of student learning. The authors plan that future publications will include catalogs of educational radio and television resources and a module to guide the implementation of effective educational activities. A number of scientists rightly draw attention to the fact that the quality of distance learning largely depends on the technological level and state of the technical devices that ensure sufficient quality of the Internet communications. Researchers note that teachers and students with "poor Internet connection" may be deprived of access to distance learning [6]. The study [7] analyzes in detail the impact of distance learning on higher engineering education. The authors note that "...since the presence of students in laboratories is very important in engineering courses, theory should be complemented by practical exercises. In this regard, virtual and remote labs can play an important role in bridging the gap between theory and practice in online courses" [7]. Both positive aspects and disadvantages of distance learning have been comprehensively considered. The study attributed the advantages of distance learning to active learning, instant feedback, self-paced and peer-to-peer learning [7]. The paper concludes fortyfive studies that online education is about as effective as classroom-based learning, and blended learning, that is, a combination of face-to-face and distance forms is more effective than either of the two [7]. The effectiveness of online distance learning is investigated in [8]. It outlines the features of developing an online course for teachers of higher education institutions. To evaluate the effectiveness of the project, the researchers conducted a multi-step survey that included both open-ended questions and judgments about certain aspects of online learning. Responses to the judgments were assessed using a summative rating method based on the Likert scale. The results of the survey indicate that the pilot course met the perceived needs and expectations of the course participants. The influence of distance learning tools on its effectiveness is considered in [9]. Researchers investigated with the involvement of thirty-six undergraduate students different ratios in combining the learning platform Moodle with traditional learning, increasing the share of distance learning. Analysis of the results allowed the authors to form conclusions that the use of information and communication technologies increased the activity of students in self-improvement of study habits, improving the cognitive, social and psychological aspects of learning. The study [10] seemed very interesting, detailed and debatable. To this end, the researchers identified three main objectives [10]. First, to identify students' motivation to learn when interacting with information technology during training. Secondly, to establish the residual knowledge of the information obtained during training after using two different methods of training. Third, to analyze a small group (six students) with special needs and how information technology affects their motivation and quality of residual knowledge. A total of 102 seventh grade students participated in the study. The students in the study were divided into three groups: two experimental and one control group. The study took place in a high school in suburban New Jersey [10]. Experimental data were collected using test methods to determine the quality of residual knowledge, Likert scale surveys, and post-project interviews. After obtaining the experimental data and analyzing them critically, the authors of the study conclude [10] that "...information technology can be a powerful educational tool for those who are interested in it".

Purpose of the study- to establish the effectiveness of teacher-student mutual communication, as well as other important elements of engineering education system: students' perception of exceptional learning conditions: degree of usefulness of methodological support; quality of educational process organization under pandemic and forced distance learning conditions.

\section{Materials and methods}

In the context of the pandemic and mandatory distance learning, a sequence of research methods united by a common goal was chosen. In this case, the resulting method was the method of summative assessments based on the Likert scale. This required some preparation: observation of the process, clarification of the stakeholders, analysis of the identified problems and contradictions, making judgments based on them, formation of cohorts and compilation of the Likert scale, calculation of 
Spearman rank correlation coefficients, etc. Three student groups from two engineering majors were involved in the study: agroengineering and industrial engineering. There were 111 people in total. The survey was conducted remotely. Respondents were sent a list of judgments about the elements of the survey through the educational-informational portal. The first survey was conducted in May 2020, the second in November 2020. For the first time, under pandemic conditions, using the methods of social psychology, the survey method and its statistical processing, the results characterizing the effectiveness of educational communications in the forced distance learning of engineers, aiming to implement selfdiagnostics of university engineering training with its subsequent improvement were obtained.

The questionnaire consisted of 22 prepared judgments divided into four judgment themes: $1 ; 5 ; 11$; 14; 20, and 22 linked respondents' opinions to the impact of distance learning on the quality of professional performance; $2 ; 7 ; 10 ; 15$ and 18 linked respondents' opinions on how distance learning is organized; $3 ; 4 ; 9 ; 12 ; 16$ and 19 linked respondents' opinions on how the quality of communication affects the effectiveness of distance learning; $6 ; 8 ; 13 ; 17$ and 21 linked respondents' opinions to the impact of digital competencies on success in the university learning and information portal environment.

Being aware of the importance of a quick response to the quarantine restrictions, we have developed and applied a refined research method - a survey and a summary assessment method based on the compilation of the Likert scale with certain specifications. We carried out the survey according to the classical schemes, described in [11-16].

The questionnaire, prepared by us, was developed as a tool capable of diagnosing with a high degree of accuracy four, in our opinion, the main components that have a decisive influence upon the quality of engineer training. Namely: organization of the training itself; the quality of communications; the level of digital competence; the future professional activity.

The content of the judgments we have developed covers the following points:

- No.1. Distant learning, matched my needs in preparation for future professional activities;

- No.2. The educational process was well organized;

- No.3. The communication channels facilitated collaboration between the teachers and the students in the group;

- No.4. The use of modern telecommunication technologies has contributed to my learning;

- No.5. The subjects of the academic disciplines included what I wanted to study in order to prepare myself for my future professional career;

- No.6. Distant learning helped me acquire skills related to digital competencies;

- No.7. The materials included in the course were a valuable contribution to my overall understanding of the discipline content;

- No.8. The media resources of the portal were useful for understanding the main topics of the disciplines studied;

- No.9. The split classes during the distant learning create an atmosphere of ease and lively communication;

- No.10. Precise logic and structured teaching materials were an important part of my training;

- No.11. Completion of the assignments included in the course were such that they contributed to the acquisition of skills for independent work;

- No.12. The online group classes gave me a rewarding interaction and learning experience;

- No.13. The e-learning course, based on the Moodle platform, is easy to navigate;

- No.14. The scope of the course assignments was adequate to the time allotted for their completion;

- No.15. The content of the subjects of the course corresponded to the curriculum;

- No.16. The system of interactive communication with the teacher has a decisive influence on my competence;

- No.17. Distant learning helps students develop their own styles of independent work;

- No.18. The content of the text, video and audio corresponded to my ideas about quality teaching;

- No.19. Distant learning contributed to the development of self-discipline and skills to meet the deadlines for completing the assignments of the study; 
- No.20. Distant learning contributed to the development of the self-development and selfeducation skills;

- No.21. By visiting the portal of educational information, it was not difficult for me to get acquainted with the educational material;

- No.22. This course helped me make sure that engineering is exactly what I want to do.

In addition, judgments: $2 ; 7 ; 10 ; 15$ and 18 drew the respondents' opinion on how distant learning is organized; $3 ; 4 ; 9 ; 12 ; 16$ and 19 attached the opinion of the respondents to the quality how communication affects the efficiency of distant learning; 6; 8; 13; 17 and 21 linked the opinion of the respondents with the influence of digital competencies upon the success of the work in the environment of the university's educational information portal; $1 ; 5 ; 11 ; 14 ; 20$ and 22 drew the respondents' opinion to the impact of distant learning upon the quality of professional activity.

The survey was conducted twice. The first in May 2020, and the second at the end of November of the same year. The surveys were conducted remotely. Three groups of students of agricultural engineering specialty and three groups of agroengineering specialty participated. The results - the answers to the judgments were evaluated by a five-point system. Statistical check of the results was carried out by calculating the correlation coefficients for each judgment.

\section{Results and discussion}

Threats to higher professional education, which manifested themselves in the past year 2020, were, above all, related to overcoming the consequences of strict quarantine restrictions. On the one hand, this exposed weaknesses in the educational process of higher education, and on the other hand, served as a powerful motivational component in the desire of the scientific and pedagogical community to implement innovative teaching technologies and teaching tools. In the scientific search for innovative technologies of training engineers in agricultural engineering, technical service and production operation, the urgent task of creating conditions ensuring effective professional development of the students' creative potential is brought to the forefront [11]. The engineer of modern agricultural production, due to the circumstances stated above, is simply obliged to improve himself, that is - to have strong skills of creative professional self-learning [12]. It is possible to achieve a high level of development and training of future professionals through new approaches to the content and organization of distance learning.

A total of 68.67\% of respondents responded "Strongly Agree" and "Agree" in May 2020; 6.43\% of respondents "Disagree" and "Strongly Disagree", with $21.70 \%$ of respondents choosing "Partly Agree" and "Partly Disagree". The average score across the sample was 3.96 points, with the value of the coefficients across the samples ranging from $r_{s}=0.44$ (judgement No 20) to $r_{s}=0.68$ (judgement No. 9). Fig. 1 shows a histogram with the results of this survey.

Between May and November 2020, a number of organizational and technological measures were taken to improve the quality of distance learning in the face of increasing quarantine restrictions. Special attention was paid to the early implementation of information and multimedia technologies for individual distance learning in the educational process. Due to the main feature of professional engineering education - educational work in laboratories and on-the-job practice, the processes of updating the available presentation materials were intensified. Experience has been gained in preparing models for off-line laboratory work, when students are sent a link to an Internet resource with relevant multimedia content [2]. The practice of the so-called "split classes" was also expanded, namely, when a lecture or laboratory work is conducted online with the target audience divided into a small part of 210 students, who are in the classes "live", while the main part of the target audience participates in them remotely. At the end of November 2020, the survey with the same audience was repeated. All conditions were maintained. The statistically processed results for the first survey are presented in Fig. 1.

The results in November 2020 were as follows: "Strongly Agree" and "Agree" - 79.07\% of respondents responded, $10.4 \%$ more than in May of the same year; "Disagree" and "Strongly Disagree" were chosen by $3.52 \%$ and $6.43 \%$ of respondents respectively, $2.91 \%$ decrease from the May survey. Also, by $4.3 \%$ decreased the number of respondents who have chosen "Partly Agree", "Partly Disagree" in November $17.40 \%$ of respondents have chosen this evaluation. The average score across the sample was 4.22 points, with the value of the coefficients across the samples ranging from $r_{s}=0.39$ 
(judgement No. 14) to $r_{s}=0.71$ (judgement No. 3). Fig. 2 shows a histogram with the results of this survey.

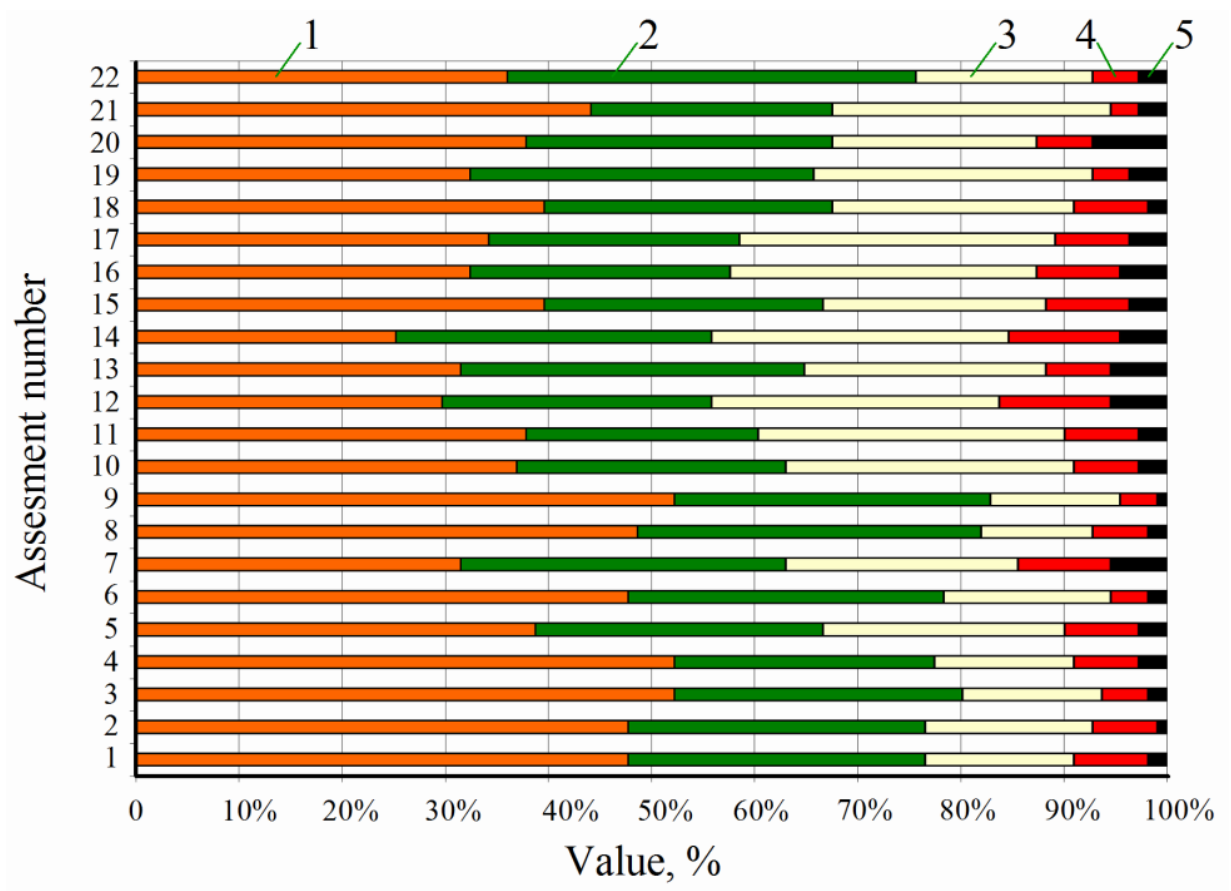

Fig. 1. Ratio of judgment estimates in the respondents' survey responses May 2020:

1 - strongly agree; 2 - agree; 3 - abstain; 4 - disagree; 5 - strongly disagree

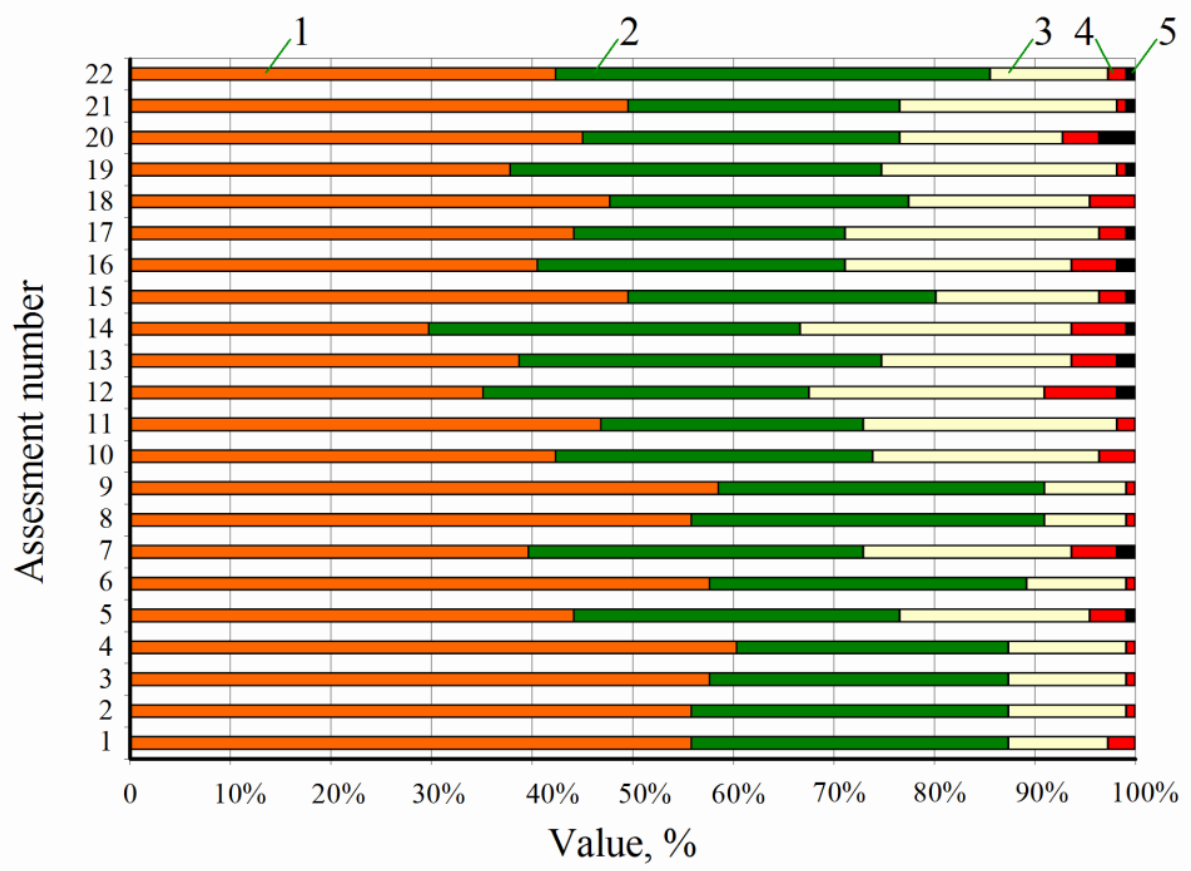

Fig. 2. Ratio of judgment ratings in respondents' survey responses in November 2020:

1 - strongly agree; 2 - agree; 3 - abstain; 4 - disagree; 5 - strongly disagree

The analysis of the results concerning the general evaluations according to the categories of judgments showed the following: judgments with the numbers: $1 ; 5 ; 11 ; 14 ; 20$ and 22 , which displayed the respondents' opinion with the impact of distance learning on the quality of professional activities improved by an average of 0.26 points; $2 ; 7 ; 10 ; 15$; and 18 , which displayed respondents' opinions on how distance learning is organized improved by 0.22 points; $3 ; 4 ; 9 ; 12 ; 16$ and 19 that displayed respondents' judgment of the quality of communication and its impact on the effectiveness of distance learning improved by 0.25 points; $6 ; 8 ; 13 ; 17$ and 21 which reflected the respondents' opinion on the 
influence of digital competences on the success of their work in the environment of the educational and information portal of the university improved by 0.26 points.

On the whole, the obtained statistical results provide grounds for the assessment of the changes that have occurred in the estimates of the obtained surveys. Fig. 3 shows the dynamics of change, i.e, comparative graphs showing part of the overall analysis and performance of the respondents' evaluations of the "Strongly Agree" category. Besides, it is obvious that Curves 1 and 2 are equidistant, which indicates the achieved efficiency of communication between the teacher and the student under the created forced and exceptional conditions of learning.

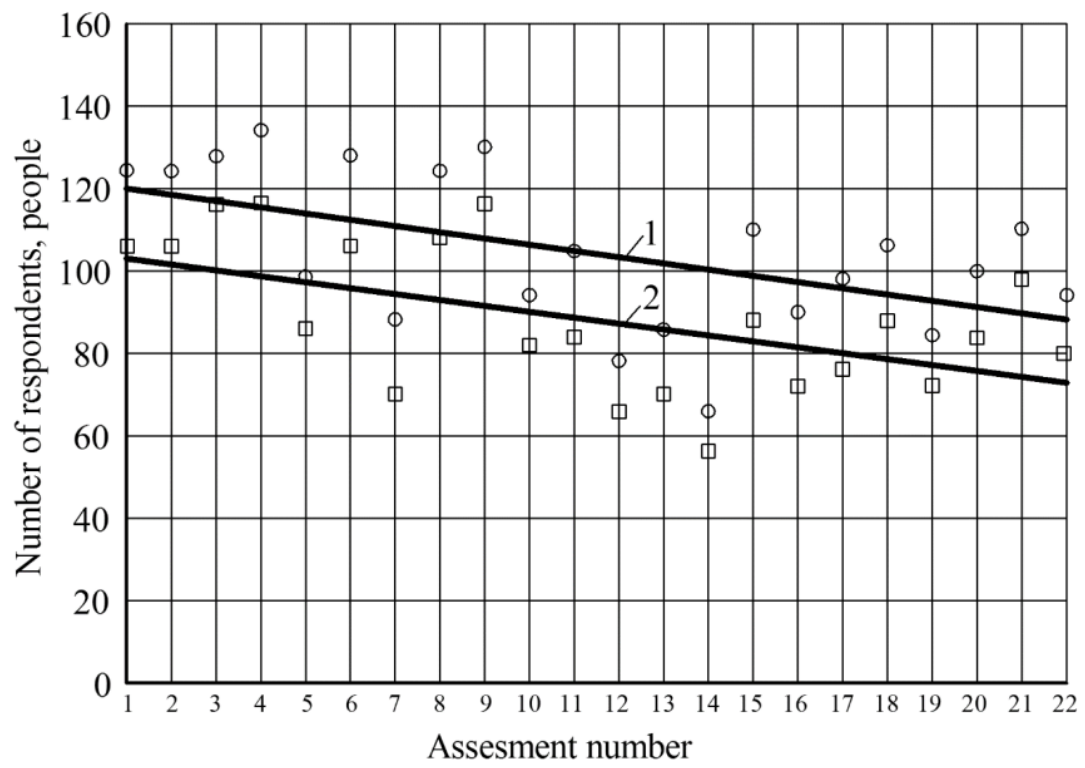

Fig. 3. Evolution of respondents' evaluations of judgments, offered in May and November 2020: 1 - strongly agree (November); 2 - strongly agree (May)

Evaluation of the effectiveness of educational communications, under the conditions of increasing quarantine restrictions, oriented the scientific and pedagogical staff of the two engineering faculties to search for ways to improve the organizational component of distance learning. This process should serve the main objectives of the productive learning process, regardless of the form of its implementation: in the regular and distance forms.

\section{Conclusions}

1. Analysis of the data obtained in the course of a survey of 111 students with using an appropriate mathematical apparatus of scientific and applied research (IBM SPSS Statistics) makes it possible to ascertain the reliability of the developed and applied new questionnaire as a research tool (Cronbach's alpha coefficient was 0.87).

2. As a result of the organizational and technological measures that we have carried out, aimed at the improvement of the quality of distant learning under the conditions of increasing quarantine restrictions, noticeable positive trends have appeared over six months of observations. Thus, judgments reflecting the impact of distant learning upon the quality of professional activity improved by an average of 0.26 points, and the assessment of the organization of distant learning improved by 0.22 points. The respondents' opinion on the quality of communications and their impact upon the efficiency of distant learning improved by 0.25 points.

3. The opinion of the respondents on the impact of digital competencies upon the success of their work in the environment of the university educational information portal also improved by 0.26 points.

\section{References}

[1] Education during COVID-19 and beyond. Policy Brief. August 2020. [online] [21.03.2021] Available at: https://www.un.org/development/desa/dspd/wpcontent/uploads/sites/22/2020/08/sg_policy_brief_covid-19_and_education_august_2020.pdf

[2] Educational and informational portal of the NUBiP of Ukraine. Available at: http://nubip.edu.ua/. 
[3] Regulations about the initial information portal of the NUBIP of Ukraine. [online] [21.03.2021] Available at: https://nubip.edu.ua/sites/default/files/u284/polozhennya_pro_nip-20211.docx

[4] Egodawatte G. An analysis of the competency-based secondary mathematics curriculum in Sri Lanka. Educational Research for Policy and Practice, Vol. 13 (1), 2014, pp. 45-63.

[5] Reimers F., Schleicher A., Saavedra J., Tuominen S. Supporting Continuing Teaching and Learning During the COVID-19 Pandemic. Oecd, 1 (1), 2020, pp. 1-38

[6] Hodson D. Philosophy of Science, Science and Science Education. Journal of Philosophy of Education. Vol.20, 2006, pp. 215-225.

[7] Reimers F., Schleicher A., Saavedra J. Tuominen S. Supporting the continuation of teaching and learning during the COVID-19 Pandemic Annotated resources for online learning. Oecd, 1 (1), 2020, pp. 1-38.

[8] Olasile Babatunde Adedoyin, Emrah Soykan. Covid-19 pandemic and online learning: the challenges and opportunities, Interactive Learning Environments. 2020. Available at: DOI: $10.1080 / 10494820.2020 .1813180$

[9] Iqbal S. Towards MOOCs and Their Role in Engineering Education. Proceedings of 7th International Conference on Information Technology in Medicine and Education (ITME), Huangshan, China, 2015, pp. 705-709.

[10] Shattuck J., Dubins B., Zilberman D. Maryland Online's Inter-Institutional Project to Train Higher Education Adjunct Faculty to Teach Online. International Review of Research in Open and Distance Learning. Vol.12.2, 2011, pp. 40-61.

[11]Bed Prasad Dhakal, Lekhnath Sharma. Virtual Learning Environment (VLE) in Mathematics Education. Education Journal. Vol. 5(6), 2016, pp. 126-135

[12] Granito M., Chernobilsky E. The Effect of Technology on a Student's Motivation and Knowledge Retention. NERA Conference Proceedings, 2012, Paper 17

[13] Nikolaenko S., Bondar M., Bulgakova O., Dukulis I. Investigation of pedagogical conditions for development of professional self-perfection skills of future agricultural engineers. Engineering for rural development. Vol. 19, 2020, art. 337.

[14] Nikolaenko S., Bondar M., Bulgakova O., Vartukapteinis K. Possibilities to control students' knowledge while trained for their future occupation in field of agricultural engineering. Engineering for rural development. Vol. 19, 2020, art. 336.

[15] Магсумовна К.Г., Борисовна В.В., Геннадьевна П.О. Использование шкалы Лайкерта при исследовании мотивационных факторов обучающихся (The use of the Likert scale in the study of motivational factors of students). Kiev, 2018, 56 p. (In Russian)

[16] Spooren P., Mortelmans D., Denekens, J. Student evaluation of teaching quality in higher education: Development of an instrument based on 10 Likert-scales. Assessment \& Evaluation in Higher Education. Vol.32, 2008, pp. 667-679. 